\title{
Technology-enhanced Self-directed Language Learning Behaviors of EFL Student Teachers
}

\author{
Sayed Masood Haidari \\ Mersin University, Turkey \\ ORCID: 0000-0003-3221-6343 \\ Tugba Yanpar Yelken \\ Mersin University, Turkey \\ ORCID: 0000-0002-0800-4802 \\ Cenk Akay \\ Mersin University, Turkey \\ ORCID: 0000-000-9892-6255
}

\begin{abstract}
English as a Foreign Language ( $E F L$ ) education not only requires students to receive in-class instruction but also necessitates them to engage in extra practices outside the classroom by using technological or non-technological resources. Hence, this study aimed to investigate the self-directed language learning behaviors of the EFL student teachers and their use of technology in the process by employing a mixed-methods study within an explanatory sequential research design. The quantitative data were collected from $110 \mathrm{EFL}$ student teachers by using two distinct research instruments, whereas the qualitative data were collected through an open-ended questionnaire form, responded by 47 of these students. The results of the study indicated that technology utilization is a significant predictor of self-directed language learning. However, the findings show that the offcampus self-directed language learning abilities of the students, with or without the use of technology, do not significantly differ according to gender, age, and grade levels. The differences were only found in terms of unaided off-campus learning abilities of the students and their technology utilization frequency in language learning. The qualitative findings also show that students engage in a variety of self-directed language learning activities outside the classroom mostly by using technology.
\end{abstract}

Keywords: Technology-enhanced learning; Self-directed learning; EFL student teachers; Language learning

\section{Introduction}

Education systems are changing dramatically in the current digitalized world with the integration of modern technology into the education paradigm. This has, in fact, facilitated the rapid flow of new bodies of knowledge in different fields of education and has put a positive impact on the teaching and learning process. In the meantime, the growing demands of the society bear the necessity to consider the inclusion of new content knowledge in school curriculum and to facilitate acquisition of new skills to the students. Keeping this in mind, teachers should be 
familiarized with the self-directed nature of learning and be equipped with the essential skills to benefit from a large amount of emerging knowledge in the field of their studies through technological and non-technological resources. According to Selwyn (2006), technology has made learning accessible to everyone almost anywhere in the world by enabling individuals to engage in a more independent way of learning. This way, they can self-access large amounts of essential information and resources available in different forms and formats in order to develop their existing knowledge and skills. Herein, teacher education programs carry the responsibility of educating able teachers to promote the quality of education by making the instructional technology an integral part of their teaching career.

As pointed out earlier, technology has positively affected every field of education. Of these educational fields, English as a Foreign Language (EFL) education has evolved more rapidly in recent years than any other language in the world especially through the incorporation of technology. Richards (2015) states that the Internet and other technological devices enable free access to large amounts of materials, applications, and language learning programs, which, in turn, help students to improve their language skills in or out of the classroom. Language learning requires plenty of active practice both inside and outside of the classroom either independently or under the guidance of capable others. Therefore, students can be encouraged to learn or practice their EFL skills by using technology in a more self-directed way of learning. Self-directed learning (SDL) can be integrated into different subject areas to guide the learners towards more independent learning strategies, for its necessity is felt in later phases of their lives (Gibbons, 2002). However, incorporation of technology in SDL could widen students' learning scope. Conversely, the reliance of the students on learning English only in the classroom context limits the improvement of their language skills. The use of technology in language learning diminishes this limitation by allowing the students to practice their language skills wherever they wish (Richards, 2015).

There is a wide range of research with regard to the use of technology in foreign language education in different educational levels. However, technology-supported SDL in EFL teacher education programs seems to be an insufficiently investigated area in Turkey as noticed during the literature review. This study is assumed to provide some awareness regarding the current technology-enhanced self-directed language learning practices amongt the EFL student teachers. Therefore, this study aimed to investigate the impact of technology utilization behaviors of the EFL student teachers on their self-directed language learning behaviors and to see if these behaviors significantly differ according to different variables. It was also aimed to explore the types of SDL activities practiced, student views regarding the role of the teacher, and the contribution of technology in the process. However, first of all, the relevant literature was reviewed to provide a concise theoretical background regarding SDL and technologyenhanced SDL in EFL learning.

\section{Self-directed Learning}

Self-directed learning (SDL) is a learning process, where the learners take responsibility for their own learning. However, the degree of responsibility taken is related to the degree of interest, desire, and the personality traits of a person (Du Toit-Brits \& Van Zyl, 2017). Knowles (1975), who is one of the pioneers of SDL research, refers to SDL as a life-long learning process in adult education. Similarly, Suh, Wang, and Arterberry (2015) argue that "SDL is the tool to facilitate...lifelong learning" and acts as a driving force in enhancing knowledge and acquiring skills in adult education beyond the classroom context (p.688). 
Knowles's broad definition of SDL has been widely cited by many researchers in the field of education. He described SDL as "a process in which individuals take the initiative, with or without the help of others, in diagnosing their learning needs, formulating learning goals, identifying human and material resources for learning, choosing and implementing appropriate learning strategies, and evaluating learning outcomes" (Knowles, 1975, p. 18). Besides, Jennett (1992) argues that self-directed learners have many characteristics such as being "open, curious, organized, motivated, and enthusiastic" (p.101). Self-management is another quality that such learners must exhibit in carrying on SDL activities in which they can determine their learning scopes, and plan, organize, and manage their learning activities.

There are also some contradictory ideas about the SDL concept and the way it is perceived. Sometimes the self of self-directed learning may sound confusing; whether the learning takes place in isolation or in support of others with the personal desire of the learner. According to Leach (2000), researchers entertain different conception of this term by giving synonymous, but confusing alternatives like independent learning, self-teaching, self-instruction, learning in isolation and so forth. However, it is unrealistic for the learners to take responsibility for their own learning without getting assistance (Garrison, 1997; Gibbons, 2002). The learners need to acquire different learning strategies by receiving constructive feedback from an instructor, receiving support from the peers, and engaging in both independent and guided practices to become a self-directed learner (Khiat, 2015). This is because they may not have the required "skills, knowledge, and confidence to direct their own learning without guidance" (McGarell, 1996, p.496). In fact, students need a clue to figure out learning strategies by making responsible choices to tackle their learning needs (Thornton, 2010).

\section{Technology-enhanced SDL in EFL Education}

In addition to receiving in-class language instruction, students are required to engage in selfdirected language practices to improve their linguistic skills. The characteristics of SDL require them to be active agents of their own learning by taking responsibility for their personal growth (Thornton, 2010; Vu \& Shah, 2016). Richards (2015) contends that language teaching in the classroom takes place in order to prepare able individuals to utilize the language they are learning in a real social context. Therefore, developing a sense of self-directedness in EFL students will contribute to the improvement of their language proficiency via technology.

Meanwhile, the development in technology has made learning accessible almost everywhere by giving the students an opportunity to learn according to their individual needs through a selfdirected way of learning far from time and space constraints (Selwyn, 2006; Lau, 2017). However, SDL activities with or without the use of technology require facilitation, guidance, and advice on the part of the teacher. Here, the teacher plays a vital role in cultivating a sense of accountability in students to engage them in self-directed language learning by raising their learning awareness, encouraging self-assessment, and reflection on their own learning (Thornton, 2010). Students cannot act alone in this process. They have to get some sort of training and guidance to acquire the necessary skills to become independent learners over time. At this point, teachers have to perform two important tasks at the same time, that is, to teach intended content knowledge to the students and to promote their SDL capabilities by taking a facilitative role instead of being a provider of knowledge (Du, 2013). There are many studies that support the effectiveness of technology-assisted SDL in EFL education and the role of the teacher in the process. 
A study conducted with undergraduate students in Taiwan reflects the significance of a facilitator role of the teachers in students' engagement in SDL activities under their leads (Yang, 2016). The researcher found that guiding students to use online materials for learning English, encouraging them to interact with each other via technology and taking online assessments contributed significantly to their self-directed EFL learning. Likewise, in another study in Hong Kong with undergraduate foreign language students, Lai (2015) found that encouraging, guiding, and assisting students in how to use technological resources influenced their use of technology in SDL. Similarly, Lai, Li, and Wang (2017) reported that 'teachers' in-class technology-related instructional behaviors influenced students' out of class learning with technology" (p. 1122). They found that recommending useful "technological resources and shar[ing] cognitive and metacognitive strategies on how to select and use technological resources" will improve the technology-enhanced self-directed language learning abilities of the students (Lai et al, 2017, p.1123). Likewise, Rashid and Asghar (2016) found that the use of technology in general and the use of social media, in particular, were statistically significant predictors of SDL and positively related to the engagement of students in independent learning. The self-directed use of technology also indirectly improved their learning outcomes. However, students' desire for improving their own learning was found to be an important factor in the use of technology in SDL (Lee, Yeung \& Ip, 2017). The contribution of technology to the development of foreign language skills is well-documented in a review study that summarizes the result of 350 primary studies conducted by Golonka, Bowles, Frank, Richardson, and Freynik (2014).

In their review, Golonka et al (2014) concluded that incorporating technology in the classroom significantly contributes to the learning of a foreign language. It can help students enrich their vocabulary and pronunciation together with their language skills. They will also be able to fulfill the given tasks quicker by referring to the online resources available and learn the accurate use of language in an enjoyable way. Here, the collaborative role of the language teacher and the peers are of primary importance as a motivating factor. In line with this point, Buitrago (2017) investigated the effects of SDL and within-class collaborative learning on enhancing the speaking skills of undergraduate EFL students at a Colombian university. She found that when students engaged in SDL and then shared what they have learned with each other in the class, their oral communication skills improved, their language anxiety decreased, and their self-confidence enhanced. This process also helped the EFL students to maintain a sense of responsibility for their own learning.

In sum, to make the EFL teaching and learning processes productive, the classes should be dynamic, socially active and participatory, where the teacher introduces authentic ways of language practice by using technology in the classrooms or recommending useful technological resources to the students to get inspired about how to select or use them out of the classroom context. A wide range of technological devices such as smart-phones, computers, and the like can be used for extra after-class language study. Together with this, the internet technology can be used as an effective source for online language learning by accessing a great number of online materials, language learning websites, and downloadable applications. These sources, of course, could provide an authentic way of SDL activities to students.

\section{Research Questions}

The following questions were asked to serve the purpose of the current study: 
1- What impact does the students' use of technology outside the class have on their SDL behaviors to improve their EFL skills?

2- Do the SDL behaviors of students and their technology utilization significantly differ according to different variables (gender, age, grade level, unaided learning ability, and technology utilization frequency)?

3- What SDL activities do the students engage in to improve their EFL skills outside the class?

4- What are the views of the EFL student teachers about the role of English teacher educators in their out of class self-directed language learning activities?

5- What are the views of the EFL student teachers about the contribution of technology to their SDL practices to improve their English?

\section{Method}

The present study investigated the SDL practices of EFL student teachers with or without the use of technology through a mixed-methods research approach within an explanatory sequential design. It is an integration of quantitative and qualitative research strategies that require data collection tools from both of these research paradigms within a single study (Bryman, 2012; Gay, Mills, \& Airasian, 2012). This type of research is conducted to use the combined strength of both quantitative and qualitative research approaches to study a phenomenon in depth (Gay et al. 2012).

The qualitative data collection was considered as a secondary priority by collecting extra information to support the quantitative one. Similarly, the analyses processes of the data were carried out separately. This process is termed as explanatory sequential research design, where "the researcher first uses a quantitative method and then uses a qualitative method to follow up and refine the quantitative findings" (Fraenkel \& Wallen, 2009, p. 561; Creswell, 2012). As shown in Figure 1, the researcher separately collects and analyzes the quantitative and qualitative data in two different phases and uses the qualitative data "to help explain or elaborate on the quantitative results" (Creswell, 2012, p. 542).

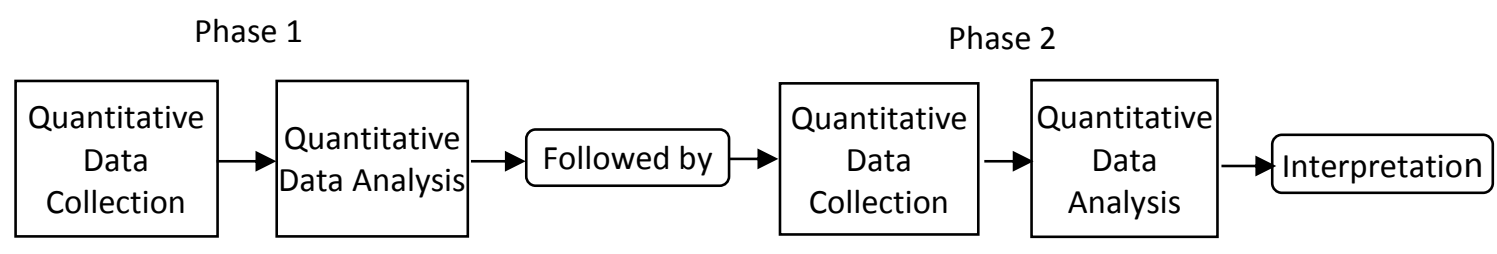

Figure 1. Data Collection and Analysis Process in Mixed-methods Research within Explanatory Sequential Design (Inspired by Creswell, 2012, p. 541)

\section{Participants}

Participants of the quantitative part of the study included 117 pre-service EFL teacher students from an education faculty of a Turkish university. However, after discarding the incomplete data, 
this number dropped to 110. Participants were selected randomly from freshmen to seniors including both male and female students with different age groups. Of these students, 81 (74\%) were female and $29(26 \%)$ male. Moreover, $44(40 \%)$ of them were freshmen, 19 (17\%) sophomores, $28(26 \%)$ juniors, and $19(17 \%)$ were seniors. They were of three different age groups, that is, 18-22 $(n=80,73 \%), 23-27(n=18,16 \%)$, and $28-32(n=12,11 \%)$. In addition, 47 of these students participated in the qualitative part of the study. All of them were selected on a voluntary basis through informed consent and protected identities in order to ensure subject confidentiality as emphasized by Christenson, Johnson, and Turner (2015).

\section{Data Collection Tools and Procedures}

Data collection took place in March and April 2018 by administering three data collection tools in two different phases. In phase one, the quantitative data were collected by administering two measurement scales: Self-Directed Learning Inventory with 28 items developed by Suh et al. (2015) and English Language Learners' Readiness Scale in Using Computer Technology for SDL with 24 items developed by Lee et al. (2017). Both of these data collection instruments were designed as five-point Likert scale with response categories ranging from strongly disagree to strongly agree. However, the analyses were carried out according to the total scores of each separate scale without considering their sub-factors. While developing these scales the researchers have applied exploratory factor analysis and then cross-validated them through confirmatory factor analysis to ensure the validity and reliability of the respective scales. As a result, the first scales accounted for $66 \%$ of variances with "a moderate fit, $X^{2}(342)=660.07, p$ $<.001 ; \mathrm{TLI}=.89 ; \mathrm{CFI}=.90 ;$ SRMR = .07; RMSEA = .05" (Suh et al, 2015, p. 691). The second scale, however, accounted for $60.4 \%$ of variances with "an acceptable fit, $X^{2}(237)=456.53, \mathrm{TLI}=0.92$, $\mathrm{CFI}=0.93$, RMSEA $=0.05$ " (Lee et al, 2017, p. 104). Moreover, the calculation of Cronbach's Alpha of first scale (Suh et al, 2015) in the present study was found to be 0.86 and for the second one (Lee et al. 2017) 0.90.

In the second phase, a questionnaire form consisting of three open-ended questions was used to collect the qualitative data as a supporting tool for measurement scales used in phase one. These questions were devised to respond to the last three research questions for the qualitative part of the study to support the findings of the quantitative portion. In order to ensure the validity and reliability of the qualitative part of the study, the opinions of two research experts were sought regarding the relevance, clarity, and understandability of the questions in the questionnaire form. After minor correctionsbased on the feedback received, the data collection process was initiated.

\section{Data Analysis}

Data analysis was carried out at two separate stages. First of all, quantitative data were entered into SPSS Release 23 and analyzed through a series of parametric tests including Simple Linear Regression, Independent Samples $t$-test, and one-way ANOVA for unrelated measures. However, in order to ensure the assumptions of these tests, the normality test of Kolmogorov Smirnov was conducted. The results showed a normal distribution across all variables $(p>0.05)$. Besides, the Levene Test of Homogeneity was applied before the ANOVA tests and results showed the variances are equal $(p>0.05)$. When significant differences were found between the variables, post hoc tests of Bonferroni and Fisher's Least Significant Difference (LSD) were 
applied to see the differences in between the sub-categories of the independent variables. As noted before, all the analyses were carried out by computing the total scores of the scales and comparing them according to different variables (gender, age group, grade level, ability to learn without receiving support and the frequency of technology utilization). In addition, the qualitative data were analyzed through a content analysis technique. The data were coded, summarized and presented in tables under specified categories. Besides, the frequencies of the codes were given along with their percentages accordingly. The coding of the raw data was carried out by two researchers. To ensure the reliability of the coding, Miles and Huberman's internal consistency test was applied (Creswell, 2009). The results of this analysis show that the mutually extracted codes were consistent by more than $90 \%$ across all three open-ended questions.

\section{Results}

This study contributed to a number of important findings with regard to the self-directed language learning practices of EFL student teachers and their use of technology in the process. All the quantitative and qualitative findings are portrayed in specific tables and elaborated in details.

\section{Quantitative Findings}

Simple linear regression was computed to investigate whether the SDL behaviors of the students was statistically predicted by technology use. Prior to that, the normal distribution of the data and positive relationships between the two variables were ensured as the pre-requisites of the regression analysis. The result of the simple linear regression, $R^{2}=0.432, F(1,108)=82.193, p<$ 0.01 , indicated that there is a significant relationship between the SDL practices of students and their use of technology in learning English independent of the classroom setting (See Table 1). Thus, the model created described $43.2 \%$ of the variances and the analyses of the standardized beta coefficient and $t$-test results, $\beta=0.657, t(4.07), p<0.01$, showed that technology utilization is a significant predictor of the SDL practices.

Table 1. Prediction of SDL by Technology Utilization in Learning EFL

\begin{tabular}{llllll}
\hline Variable & $\mathrm{B}$ & $\mathrm{SE}$ & $\beta$ & $\mathrm{t}$ & $\mathrm{p}$ \\
\hline Constant & 33.797 & 8.309 & & 4.067 & $.000^{* *}$ \\
$\mathrm{SDL}$ & .808 & .089 & .657 & 9.066 & $.000^{* *}$ \\
\hline $\mathrm{R}=0.657$ & $\mathrm{R}^{2}=0.432$ & $\mathrm{~F}(1.108)=82.193^{* *} \mathrm{p}<0.01$ & &
\end{tabular}

However, the results of the independent sample $t$-test, $t_{108}=1.68, p>.05$, yielded no significant difference between the SDL behaviors of male and female students (See Table 2). However, the mean SDL score of the female students $(M=110.07, S D=11.34)$ was slightly higher than that of males' $(M=104.72, S D=15.76)$. Similar results were also obtained regarding the technology utilization behaviors of these students in language learning $\left(t_{108}=.900, p>.05\right)$. The findings indicate that both male and female students utilize technology evenly in order to promote their EFL skills through SDL. 
Table 2. SDL Practices of EFL Students and Their Technology Utilization According to Gender

\begin{tabular}{|c|c|c|c|c|c|c|}
\hline \multirow{3}{*}{ Measures } & \multicolumn{4}{|c|}{ Gender } & \multirow[b]{3}{*}{$\mathrm{t}(108)$} & \multirow[b]{3}{*}{$p$} \\
\hline & \multicolumn{2}{|c|}{ Male $(n=29)$} & \multicolumn{2}{|c|}{ Female $(n=81)$} & & \\
\hline & $\bar{M}$ & SD & $\bar{M}$ & $\overline{S D}^{\prime}$ & & \\
\hline SDL behaviors & 104.72 & 15.77 & 110.07 & 11.34 & 1.68 & .101 \\
\hline Technology use in EFL & 90.97 & 13.03 & 93.33 & 9.33 & .900 & .374 \\
\hline
\end{tabular}

Moreover, the differences between students' SDL scores were examined according to three different age groups. As indicated in Table 3, the One-way ANOVA, $F(2,107)=1.39, p>.05$, yielded no significant differences between the SDL mean scores of the students and their age groups. However, the students within the 23-27 age group were more self-directed in improving their language skills beyond the classroom $(M=113.22, S D=13.59)$ compared to the students from other age groups.

Table 3. SDL and Technology Utilization Behaviors of EFL Students with Different Age Groups

\begin{tabular}{|c|c|c|c|c|c|c|c|c|}
\hline \multirow{3}{*}{ Measures } & \multicolumn{6}{|c|}{ Age Groups } & \multirow[b]{3}{*}{$F(2,107)$} & \multirow[b]{3}{*}{$\mathrm{p}$} \\
\hline & \multicolumn{2}{|c|}{$18-22(n=80)$} & \multicolumn{2}{|c|}{$23-27(n=18)$} & \multicolumn{2}{|c|}{$28-32(n=12)$} & & \\
\hline & $M$ & SD & $\mathrm{M}$ & SD & $\mathrm{M}$ & SD & & \\
\hline SDL behaviors & 107.85 & 12.35 & 113.22 & 13.59 & 107.25 & 14.24 & 1.39 & .255 \\
\hline Technology in EFL & 92.68 & 10.65 & 95.39 & 9.79 & 88.92 & 9.24 & 1.40 & .251 \\
\hline
\end{tabular}

Table 3 also indicates that technology utilization behaviors of the students in language learning do not significantly differ according to their age group, $F(2,107)=1.40, p>.05$. However, similar to the previous finding, the mean score $(M=95.39, S D=10.65)$ of the students aged 23-27, was found to be slightly higher compared to students from other age groups. Despite these very small differences, EFL student teachers between the stated age groups engaged evenly in SDL practices by using technology in the process.

In addition, the results of One-Way ANOVA analyses in Table 4 indicate that SDL abilities of the students, $F(3,106)=.104, p>.05$, and their technology utilization for language learning, $F(3$, $106)=.425, p>0.05$, were not statistically different in terms of grade level. Their mean scores were too close to each other in all cases. These findings prove that grade level does not show increased engagement in self-directed language learning in undergraduate EFL education with or without the use of technology.

Table 4. SDL and Technology Utilization Behaviors of Students According to Grade Levels

\begin{tabular}{|c|c|c|c|c|c|c|c|c|c|c|}
\hline \multirow{3}{*}{ Measures } & \multicolumn{8}{|c|}{ Grade Levels } & \multirow[b]{3}{*}{$F(3,106)$} & \multirow[b]{3}{*}{$p$} \\
\hline & \multicolumn{2}{|c|}{ First $(n=44)$} & \multicolumn{2}{|c|}{ Second $(n=19)$} & \multicolumn{2}{|c|}{ Third $(n=28)$} & \multicolumn{2}{|c|}{ Fourth $(n=19)$} & & \\
\hline & $M$ & SD & $\mathrm{M}$ & SD & $\mathrm{M}$ & SD & $\mathrm{M}$ & SD & & \\
\hline SDL behaviors & 107.84 & 12.06 & 109.11 & 13.31 & 109.07 & 13.41 & 109.59 & 13.97 & .104 & .957 \\
\hline Tech in EFL & 92.36 & 10.33 & 95.16 & 9.08 & 92.14 & 11.75 & 91.89 & 10.26 & .425 & .735 \\
\hline
\end{tabular}

Contrary to the findings reported previously, when the students' unaided learning ability and their SDL scores were compared, the One-way ANOVA, $F(2,107)=9.081, p<.01$, yielded a significant difference between the two variables (See Table 5). In addition, pair-wise group comparisons were made through Bonferroni post hoc analysis to see which sub-category mean differences were significant. The differences were noticed between the mean SDL score of students who said yes for totally being able to engage in unaided out-of-class SDL activities and the ones who said to some extent. 
Table 5. Unaided SDL and Technology Utilization Abilities of the Students

\begin{tabular}{|c|c|c|c|c|c|c|c|c|c|}
\hline \multirow{3}{*}{ Measures } & \multicolumn{6}{|c|}{ Able to Learn without Support } & \multirow[b]{3}{*}{$F(2,107)$} & \multirow[b]{3}{*}{$\mathrm{p}$} & \multirow{3}{*}{$\begin{array}{l}\text { Source of } \\
\text { difference }\end{array}$} \\
\hline & \multicolumn{2}{|c|}{ Yes $(n=46)$} & \multicolumn{2}{|c|}{ Some extent $(n=59)$} & \multicolumn{2}{|c|}{ No $(n=5)$} & & & \\
\hline & $M$ & SD & $\mathrm{M}$ & SD & $\mathrm{M}$ & SD & & & \\
\hline SDL behaviors & 113.39 & 11.47 & 104.22 & 12.58 & 117.60 & 6.62 & 9.081 & $.000 * *$ & $A-B$ \\
\hline Tech in EFL & 96.15 & 8.82 & 89.59 & 10.90 & 97.80 & 6.94 & 6.306 & $.003 * *$ & $A-B$ \\
\hline
\end{tabular}

Note: ${ }^{* *} p<0.01 \quad \mathrm{~A}=$ Yes $\quad \mathrm{B}=$ To some extent

Table 5 indicates that the mean score of the students who said yes for being able to learn on their own without getting support $(\mathrm{M}=113.39, \mathrm{SD}=11.47)$ was significantly larger than that of the ones who said to some extent $(\mathrm{M}=104.22, \mathrm{SD}=12.58)$. Contrarily, the mean SDL score of students who said they cannot learn on their own without receiving support is the highest $(\mathrm{M}=117.60, \mathrm{SD}=6.62)$ which is probably due to unequal cell sizes. Taken together, the majority of the students can take responsibility for their own learning by engaging in SDL activities. So, if they get some guidance on how to engage in off-campus language learning practices, they will be able to act more independently in improving their EFL skills by referring to different resources.

A similar finding was also revealed regarding technology utilization in self-directed language learning (See Table 5). The One-Way ANOVA yielded a significant difference between the technology utilization behaviors of students in language learning and the extent to which they do or do not need support in independent learning, $F(2,107)=6.306, p<0.003$. Bonferroni post hoc analyses indicated that this difference was between the student groups who said Yes ( $\mathrm{M}=$ $96.15, \mathrm{SD}=8.82)$ and To Some Extent $(\mathrm{M}=89.59, \mathrm{SD}=10.90)$ for being able to engage in unaided learning via technology. The students who were unable to learn without support were only 5 , but the mean scores related to their technology utilization behaviors for language learning is comparatively larger than others' $(M=97.80, S D=6.94)$. To elaborate more, although a majority of students $(n=59)$ needed some guidance while trying to improve their EFL skills through technology-enhanced SDL, there were many other students who totally relied on their own learning abilities without support. Besides, there were a few students, who completely relied on teachers or someone else to guide them through their learning processes.

In addition, a small significant difference was found between the frequency of technology utilization in language learning and SDL behaviors of students, $F(2,107)=3.389, p<.037$. As seen in Table 6, the LSD post hoc analysis indicated that these differences were between students who always, often or sometimes used technology for self-directed language learning.

Table 6. SDL Behaviors of Students Based on the Frequency of Their Technology Use for Language Learning

\begin{tabular}{|c|c|c|c|c|c|c|c|c|c|}
\hline \multirow[b]{3}{*}{ Measure } & \multicolumn{6}{|c|}{ Technology Utilization Frequency } & \multirow[b]{3}{*}{$F(2,107)$} & \multirow[b]{3}{*}{$\mathrm{P}$} & \multirow{3}{*}{$\begin{array}{l}\text { Source of } \\
\text { Difference }\end{array}$} \\
\hline & \multicolumn{2}{|c|}{ Always ( $n=32$ ) } & \multicolumn{2}{|c|}{ Often $(n=63)$} & \multicolumn{2}{|c|}{ Sometimes $(n=15)$} & & & \\
\hline & M & SD & $\mathrm{M}$ & SD & $\mathrm{M}$ & SD & & & \\
\hline $\begin{array}{l}\text { SDL } \\
\text { Behaviors }\end{array}$ & 113.39 & 11.47 & 106.95 & 12.71 & 105.60 & 13.04 & 3.389 & $.037^{*}$ & $A-B, C-A$ \\
\hline
\end{tabular}

Note: ${ }^{*} p<0.05 \quad \mathrm{~A}=$ Always $\quad \mathrm{B}=$ Often $\quad \mathrm{C}=$ Sometimes

Besides, the arithmetic mean score of students who always used technology in SDL for improving their EFL skills was comparatively larger than that of the others $(M=113.47, S D=11.92)$. 
However, the mean scores of students who often or sometimes used technology in self-directed language learning were relatively similar $(M=106.95, S D=12.71$ and $M=105.60$, SD $=13.04$, respectively). In general, these findings show that the more students use technology for improving their EFL skills, the more self-directed they will become in their own learning. So doing, they will start feeling responsible for their personal growth.

\section{Qualitative Findings}

\section{Out of Class SDL Activities of the EFL Students}

As seen in Table 7, the EFL student teachers engage in various self-initiated activities in order to improve their EFL skills independent of the classroom environment. One of the most prevalent and most frequently stated self-engaged activities amongst the students was watching videos, movies or TV series for developing their overall EFL skills $(f=26,37 \%)$. Further, the results of the study show that students prefer to watch subtitled videos in order to understand what is being said. One of the students mentioned, "I always watch subtitled TV series outside the classroom and I noticed that my listening and speaking skills have improved over time" (S33).

Table 7. Students' Out of Class SDL Activities in Improving Their EFL Skills ( $N=47)$

\begin{tabular}{llll}
\hline Theme & Codes & $f$ & $\%$ \\
\hline & Watching videos/movies/TV series & 26 & 37.14 \\
& Listening to music/audio clips & 13 & 18.57 \\
& Speaking with native speakers & 13 & 18.57 \\
Self-engaged & Reading (books/newspapers) & 7 & 10 \\
Activities & Playing games & 4 & 5.71 \\
& Looking for alternative ways to practice English & 4 & 5.71 \\
& Writing (to friends, short stories) & 3 & 4.29 \\
\cline { 2 - 4 } & Total & 70 & 100.00 \\
\hline
\end{tabular}

Besides, listening to music was mentioned in combination with watching videos as another activity in language practice $(f=13,19 \%)$. One of the students put this way: "Listening to music and watching TV series in target language helps me learn the pronunciation of the words" (S36). It was also found that when students listen to the songs, they try to access the lyrics in order to understand the type of language used in the songs. By referring to lyrics, they improved their vocabulary and language patterns used in them as illuminated in a student's response. "I always check the lyrics of the songs I like. I learn many grammatical patterns and new words from songs" (S44).

In a similar fashion, it was found that the students tried to chat or speak with the native speakers through the internet aiming to practice their EFL skills. One of them stated "I chat with my foreign friends every day. We even make voice calls sometimes" (S31) while another one said, "I like chatting with foreigners and it improves my writing skills" (S44). Reading various types of English books, articles and newspapers via technology and traditional methods were also prevalent to some extent as mentioned by the students $(f=7,10 \%)$. Moreover, playing games for improving their English was another activity stated by a few numbers of students; although they did not make it clear how. Students also engaged some alternative ways to practice their English like: "memorizing/learning new vocabularies and using them efficiently (S14), "attending conferences over various topics" (S32) or doing "translation from English to Turkish, or Turkish to English" (S45). Writing practices were found to be the least prevalent out of class activities 
which were only mentioned in three cases where they stated that they write short stories in their notebooks or write to their friends via social networks in order to improve their writing skills in English.

\section{Role of the Teacher in EFL Students' SDL Activities}

The role of the teachers in students' out of class self-directed language learning activities was perceived to be more like a recommending agent of learning resources in the process $(f=13$, $28 \%$, see Table 8). They were expected to direct students to the authentic resources which could contribute to enhancing their EFL skills. For instance, they can recommend resources such as specific applications designed for learning English, useful books, websites and many more. According to one of the students, teachers should "suggest sources like books, and applications to students" (S12). Another student had a similar remark: "Teachers suggest us to read English novels, books, or magazines" (S45).

Table 8. The Role of Teachers in Students' Self-directed Language Learning $(\mathrm{N}=47)$

\begin{tabular}{llll}
\hline Theme & Codes & $\mathrm{f}$ & $\%$ \\
\hline \multirow{4}{*}{ Teacher's } & Recommending learning resources & 13 & 27.66 \\
Role & Guiding and supporting students & 13 & 27.66 \\
& Not having any role & 9 & 19.15 \\
& Motivating and encouraging students in learning & 7 & 14.89 \\
& Giving homework/assignments & 5 & 10.64 \\
\cline { 2 - 4 } & Total & 47 & 100.00 \\
\hline
\end{tabular}

Teachers were seen as guides and supporters in students' SDL activities to develop the students' EFL skills $(f=13,28 \%)$. They were expected to facilitate students' learning by giving feedback, supporting and guiding them on how to learn independently outside the classroom context by controlling their own progress in learning. One of the students stated that the "English teachers guide students with choosing the type of activities" (S44). Another two students mentioned that the teachers as "facilitators should direct the learners for out of class learning" (S1) and make "students aware of the types of technologies that they can use in order to improve themselves.... making them realize the outcome of their learning" (S17).

Motivating and encouraging students in SDL practices were amongst the other perceived roles of the teachers $(f=7,15 \%)$. The students just sufficed by saying that the teachers should, "encourage their students to be familiar with the language" (S3), "motivate" (S1), and "help them love English with more creative ways" (S14). However, giving homework or assignments to the students were among the least frequently stated roles of the teachers as SDL activities. It is evidenced in a student's comments: "The homework or the group assignments that the teachers give help us a lot in improving ourselves outside the classroom" (43).

The findings regarding the role of the teacher in students' self-directed language learning supported each other to a great extent. However, to some students teachers did not have any role in students' SDL practices outside the classroom environment $(f=9,19 \%)$. Students are the ones who decide what to do and what resources to use for their personal growth. They believed that "teachers do not have an effective role" (S47) in their SDL activities and "it's not about teachers because a student improves himself/herself" (S19). 


\section{The Contribution of Technology in EFL Students' SDL}

When EFL students were asked about the contribution of technology in their self-directed language learning, they most frequently stated that it enables them to access unlimited authentic materials and resources to practice English in different ways $f=21,39.62 \%$, see Table 9). These resources are available in the form of videos, audio clips, and texts which are easily accessed through the internet or technological devices. "Thanks to technology, we reach everything, everywhere..." (S10). One of the students put this way: "There are unlimited videos, audio clips, films, and books over the internet, which give us an open hand to learn more English". Whenever needed, individual can access authentic resources through the technology to uplift their EFL skills as illuminated in one of the students' comments: "Technology and the internet make it possible to access different types of information when necessary" (S44).

Table 9. Contribution of Technology-assisted SDL in Students' EFL Learning Process ( $N=47)$

\begin{tabular}{llll}
\hline Theme & Codes & $\mathrm{f}$ & $\%$ \\
\hline & Accessing Resources or materials & 21 & 39.62 \\
& Accessing Apps/programs for learning English & 7 & 13.21 \\
\multirow{3}{*}{ Tech-Assisted } & Making language learning quick and easy & 7 & 13.21 \\
SDL & Making language learning motivating \& enjoyable & 6 & 11.32 \\
& Connecting with native speakers & 6 & 11.32 \\
& Making language learning more efficient & 6 & 11.32 \\
\cline { 2 - 4 } & Total & 53 & 100.00 \\
\hline
\end{tabular}

Another facility that the technology provides for the students to develop their EFL skills is to access a variety of programs or applications which are specifically designed for learning or practicing English $(f=7,13 \%)$. For instance, one of the students stated, "we can use the programs that are created for language learning" (S10). Another one said: "Some mobile phone dictionary programs help us to practice our English skills (e.g. reading). In those programs, there are so many activities such as fill-in-blanks activities" (S45).

Students also believed that utilizing the aforementioned technological resources in out of class self-directed language learning activities makes learning quick and easy $(f=7,13 \%)$. One of the participants of the study stated that "technology is effective in accelerating and facilitating learning" (S46). Students also declared that using technology in SDL made language learning both motivating and enjoyable. Besides, it gives them an opportunity to connect with native speakers over the internet in order to improve their listening and speaking skills in particular and other aspects of the target language in general. The study also revealed that technology use in self-directed language learning process positively affected EFL students' language proficiency.

\section{Discussion}

Technology-enhanced SDL activities contribute a lot to the development of language skills of the EFL students. A large body of research evidence in the literature emphasizes the effectiveness of technology-assisted teaching and learning; including the current study. The study revealed that the use of technology increases the self-directed language learning practices amongst the students as its significant predictor. The results of the qualitative data also indicated that technology enables students to access unlimited materials of various types that make learning 
quicker, easier, and more enjoyable even if they do not get any support in the process. Once the students get familiar with authentic resources and materials (i.e. websites, language learning applications, reading materials...) to improve their English proficiency, they might get motivated to engage in SDL activities regardless of gender, age or educational level. Bullock (2013) argues that the integration of digital technologies in SDL activities can positively "change the degree to which people engage" in meaningful learning activities (p. 110). Thus, persuading students towards self-directed use of technology is imperative to maximize their technology utilization behavior in language learning (Lai, 2013). Richards (2015) argues that students will benefit more from independent language learning opportunities if they realize the significance of using technological resources beyond class hours.

This study also found that there are no significant differences amongst the SDL behaviors of students with or without the use of technology according to gender, age, and grade levels. The mean scores of the SDL and technology-enhanced SDL practices of the students were also found to be very similar in all cases. This could be because of the availability of different learning resources to Turkish students by means of technology and their familiarity with the use of various technological tools. In a study in Turkey, it was found that besides being acquainted with the utilization of different technological tools, applications, and websites, student teachers of both sexes often benefitted from the teachers' guidance (Cuhadar \& Yucel, 2010). In addition, research findings indicate that that out-of-class language learning behaviors of EFL students significantly differ in terms of their language proficiency level but not according to their gender (Eksi \& Aydin, 2013; Orhon, 2018). In contrast, Xodabande (2018) found significant differences only in terms of listening to music and playing computer games among Iranian students from a gender perspective. He reported that female students mostly listened to music, while males played computer games as part of their SDL activities. However, he suggested that gender does not have any role in self-directed use of technology in general. Although Iranian EFL students have equal access to the same materials, their personal preferences vary in terms of using technological resources for self-directed language learning.

Furthermore, the qualitative part of the current study revealed that the internet is an effective source for the students to access invaluable materials and to connect with native speakers. The videos, movies, TV series, songs, audio clips, language learning applications and games, websites, and online EFL learning platforms were a number of resources they accessed through the internet and other sources. These findings are well-supported in the existing research (Cetin, Sozcu, \& Kinay, 2012; Golonka et al, 2014; Grover, Miller, Swearingen, \& Wood, 2014; Inozu, Sahinkarakas, \& Yumru, 2010; Orhon, 2018). Grover et al (2014) reported that students who learned English as a second language used a number of strategies to develop their language skills outside the classroom. For example, they spent time with native speakers, referred to online materials, watched English programs, and used technological tools like tablets and computers to name a few. Similarly, Orhon (2018) reported that Turkish undergraduate EFL students "mostly engaged in [self-directed] listening and watching activities" (p. 1). Contrarily, some research findings also indicate that EFL students are incapable of taking responsibility for their own learning, but rely on their teachers and peers to provide recommendations and guidance on how to select learning materials for SDL activities (Eksi \& Aydin, 2013; Inozu et al, 2010).

However, the present study revealed that there are many students who engage in self-directed language learning without receiving support from the teacher or another person, and some others who need a little bit guidance or support in the process. The same situation also applies to the self-directed technology utilization of the students for their out-of-class independent language learning. These findings were also supported by the qualitative findings of the study. 
According to some students, the teacher should recommend authentic resources, guide, and motivate them in independent learning, while some other students thought that the teachers do not have any role in their learning outside the classroom. In line with these findings, Gibbons (2002) and Khait (2015) argue that students need support and direction in order to get motivated in carrying out their SDL practices. However, students who are able to carry out their EFL learning activities without relying upon others can be counted as a positive sign of maintaining attitudes of self-reliance and individual accountability in learning.

Furthermore, according to the findings of Du Toit-Brits and Van Zyl (2017), student teachers believed "that the word self in SDL simply implies that you yourself must learn" and the "learning takes place in isolation" (p. 129). Nonetheless, entertaining the idea of "isolated learning" in mind is a negative perception as regards SDL, which may have a negative impact on in-class instructions both for the teacher and the learners. It means that even if the students think that they do not need the support or guidance of the teachers in their SDL practices, at some points receiving feedback concerning the successful accomplishment of tasks is indispensable. Hereby, the recommendation of suitable learning resources would contribute to the enrichment of their SDL practices. Lai (2017) maintains that pedagogical practices of the teachers also influence technology-aided self-directed language learning behaviors of foreign language learners. Therefore, teachers are required to be well-informed of different strategies that might influence the SDL abilities of the students beyond the classroom context.

Further, the results of the study indicate that the students who use technology on a regular basis often or sometimes showed significant differences in terms of their frequency of use. It proves that the more frequently students utilize technology in language learning, the more self-directed they will become in their educational life. This finding indicates that the students will get motivated to discover new ways of learning other than relying on classroom instruction or being always directed by others. Students confirmed that technology affects their learning positively by making their learning quick and easy, but in an interesting way. They also engaged in different kinds of activities by using different technological resources to improve different aspects of their EFL skills. These findings could be related to the degree of willingness and personal motivation of the students that act as a driving force to persuade them in technology-enhanced SDL activities to improve their language skills. Lai (2013) found a number of "attitudinal factors" that influenced students' "willingness to use technology" in self-directed language learning (p. 114). These factors included students' motivation, perceived effectiveness of technology for language learning, and the adaptability of technology with the expected learning outcomes.

Taken together, most of the self-directed language learning practices of the EFL student teachers seemingly take place by using technological resources. In fact, it has become an inevitable part of their language education. To put another way, self-relying characteristics of the student teachers in their out-of-class independent language learning activities show their deep interest in EFL. Only some of them felt the necessity for some external motivation or assistance so that they could learn how to take responsibility for their own learning. One of the purposes of encouraging students in SDL activities is to boost up a sense of accountability for their personal progress (Du Toit-Brits \& Zyl, 2017).

The findings of this study indicate that self-directed language learning behaviors of the EFL student teachers by using technology not only positively affect their linguistic knowledge and language skill but also generate a sense of individual accountability towards their personal growth. This will, in turn, contribute to their later professional life by producing responsible and creative English teachers. Owning such characteristics may transform how the EFL teaching and 
learning process is seen in teacher education programs and schools thereafter. As discussed before, encouraging students towards self-directed learning will raise their self-awareness about their potential abilities. Most important, role-modeling the use of technological resources in the classroom environment in an effective way might trigger intrinsic motivation in students to engage in technology-enhanced SDL activities outside the classroom context. This would, of course, apply both in pre-service EFL teacher education programs as well as the others.

This study has some limitations. The first limitation could be with the data collection strategy used in the qualitative part of the study, where some of the written responses to the openended questions in the questionnaire were not clear enough. For instance, some of the students have written that they engage in playing games as an SDL activity in order to improve their EFL skills without explaining how. Here, conducting a semi-structured interview with them would have been more useful in getting such issues clarified by asking extra questions. Secondly, there is an issue of generalization of the findings. At the time of the study, the sample selected in the current study all lived in a country where they could easily access both technological and nontechnological resources. If it was conducted with the students who have limited access to such resources could have ended up with totally different results. Moreover, the insignificant differences found in the study, might be because of unequal number of students in the subgroups in terms of gender and age groups. Therefore, a similar study could be conducted with somewhat equal number of students in each sub-group. The following recommendations are made for further investigation concerning the technology-enhanced SDL:

- Exploring the views of the college or school students about their SDL practices to learn EFL with or without the use of technology through in-depth semi-structured interviews.

- Investigating how the teachers keep track of students' progress in their self-directed language learning via technology and the ways they manage solving the raising problems the students may face in the process.

- Investigating problems that students may encounter while trying to engage in out-ofclass SDL activities with or without the use of technology.

- Investigating the self-directed language learning practices of school or college students who have limited access to technological resources and what could be done in such kinds of situations.

\section{References}

Bryman, A. (2012). Social research methods ( $4^{\text {th }}$ ed.). Oxford: Oxford University Press.

Buitrago, A. G. (2017) Collaborative and self-directed learning strategies to promote fluent EFL speakers. English Language Teaching, 10, 139-157. doi:10.5539/elt.v10n5p139.

Bullock, S. M. (2013). Using digital technologies to support Self-Directed Learning of preservice teacher education. The Curriculum Journal, 24, 103-120. doi.org/10.1080/09585176. 2012.744695

Cetin, Y., Sozcu, O. F., \& Kiniy, H. (2012). Incidental foreign language vocabulary acquisition from social network games. International Journal of Human Sciences, 9(2), 535-552.

Christensen, L. B., Johnson, R. B., \& Turner, L. A. (2015). Research methods, design, and analysis (12 ${ }^{\text {th }}$ ed.). Courier/Westford: Pearson Education Limited. 
Creswell, J. W. (2009). Research design: Qualitative, quantitative, and mixed methods approaches $\left(3^{\text {rd }} \mathrm{Ed}\right)$. New York: Sage.

Creswell, J. W. (2012). Educational research: Planning, conducting, and evaluating quantitative and qualitative research $\left(4^{\text {th }} \mathrm{Ed}\right)$. New York: Pearson Education.

Cuhadar, C. \& Yucel, M. (2010). Perceptions of Foreign language education pre-service teachers on educational use of information and communication technologies. Pamukkale University Journal of Education, 27, 199-210.

Du Toit-Brits, C. \& Van Zyl, C. M. (2017). Self-directed learning characteristics: Making learning personal, empowering and successful. Africa Education Review, 14, 122-141. doi:10.1080/18146627.2016.1267576

Du, F. (2013). Students' perspectives of self-directed language learning: Implications for teaching and research. International Journal for Scholarship of Teaching and Learning, 7(2). doi:10.20429/ijsotl.2013.070224

Eksi, G. \& Aydin, H. (2013). What are the students doing out there? An investigation of out-ofclass language learning activities. AlBU Journal of Social Sciences, 13(2), 191-210.

Fraenkel, J. R. \& Wallen, N. E. (2009). How to design and evaluate research in education $\left(7^{\text {th }}\right.$ ed.). New York: McGraw-Hill.

Garrison, D. R. (1997). Self-directed learning: Toward a comprehensive model. Adult Education Quarterly, 48, 18-33. doi: 10.1177/074171369704800103

Gay, L. R., Mills, G. E., \& Airasian, P. (2012). Educational research: Competencies for analysis and application (10 ${ }^{\text {th }}$ ed.). USA: Pearson Education.

Gibbons, M. (2002). The self-directed learning handbook: Challenging adolescent students to excel. Hoboken, NJ: Jossey-Bass/John Wiley \& Sons.

Golonka, E. M., Bowles, A. R., Frank, V. M., Richardson, D. L., \& Freynik, S. (2014). Technologies for foreign language learning: A review of technology types and their effectiveness. Computer Assisted Language Learning, 27, 70-105. doi:10.1080/09588221.2012.700315

Grover, K. S., Miller, M. T., Swearingen, B., \& Wood, N. (2014). An examination of the selfdirected learning practices of ESL adult language learners. Journal of Adult Education, 43(2), 12-19.

Inozu, J., Sahinkarakas, S., \& Yumru, H. (2010). The nature of language learning experiences beyond the classroom and its learning outcomes. US-China Foreign Language, 8(1), 1419.

Jennett, P. A. (1992). Self-directed learning: A pragmatic view. The Journal of Continuing Education in the Health Professions, 12, 99-104.

Khiat, H. (2015). Measuring self-directed learning: A diagnostic tool for adult learners. Journal of University \& Learning Practice, 12(2). Retrieved on 19 September 2018 from http://ro.uow.edu.au/jutlp/vol12/iss2/2

Knowles, M. S. (1975). Self-directed learning: a guide for learners and teachers. Englewood Cliffs, NJ: Cambridge Adult Education.

Lai, C. (2013). A framework for developing self-directed technology use for language learning. Language Learning \& Technology, 17, 100-122. 
Lai, C. (2015). Modeling teachers' influence on learners' self-directed use of technology for language learning outside of the classroom. Computer \& Education, 82, 74-83.

Lai, C., Li, X., \& Wang, Q. (2017). Students' perceptions of teacher impact on their self-directed language learning with technology beyond the classroom: cases of Hong Kong and U.S. Education Technology Research \& Development, 65, 1105-1133. doi: 10.1007/s11423017-9523-4

Lau, K. (2017). To be or not to be: Understanding university academic English teachers' perceptions of assessing self-directed learning. Innovations in Education and Teaching International, 55(2), 201-211. doi: 10.1080/14703297.2017.1292942

Leach, L. (2000). Self-directed learning: Theory and practice (Unpublished doctoral dissertation). University of Technology, Sydney.

Lee, D., Yeung, A. S., \& Ip, T. (2017). University English language learners' readiness to use computer technology for self-directed learning. System, 67, 99-110. doi: 10.1016/j. system.2017.05.001.

McGarrell, H. M. (1996). Self-directed learning contracts to individualize language learning in the classroom. Foreign Language Annuals, 29(3), 495-508.

Orhon, Y. (2018). An investigation of out-of-class language activities of tertiary level EFL learners. Education Reform Journal, 3(1), 1-14.

Rashid, T. \& Asghar, H. M. (2016). Technology use, self-directed learning, student engagement and academic performance: Examining the interrelations. Computer in Human Behavior, 63, 604-612. doi: 10.1016/j.chb.2016.05.084

Richards, J. C. (2015). The changing face of language learning: Learning beyond the classroom. RELC Journal, 46(1). doi: 10.1177/0033688214561621

Selwyn, N. (2006). ICT in adult education: Defining the territory. In D. A., Wagner \& R. Sweet (Eds.), ICT and learning: Supporting out-of-school youth and adults (pp. 13-42). Paris: OECD. doi:10.1787/9789264012288-en

Suh, H. N., Wang, K. T., \& Arterberry, B. J. (2015). Development and initial validation of the self-directed learning inventory with Korean college students. Journal of Psychoeducational Assessment, 33, 687-697. doi:10.1177/0734282914557728

Thornton, K. (2010). Supporting self-directed learning: A framework for teachers. Language Education in Asia, 1, 158-170. doi:10.5746/LEiA/10/V1/A14/Thornton

Vu, H. Y. \& Shah, M. (2016) Vietnamese students' self-direction in learning English listening skills. Asian Englishes, 18, 53-66. doi:10.1080/13488678.2015.1136104

Xodabande, I. (2018). Iranian EFL learners' preferences of different digital technologies for language learning beyond the classroom. International Journal of Education \& Literacy Studies, 6, 20-31. doi.org/10.7575/aiac.ijels.v.6n.3p.20

Yang, Y. F. (2016). Self-directed learning to develop autonomy in an online ESP community. Interactive Learning Environments, 24, 1629-1646. doi: 10.1080/10494820.2015. 1041402.

Correspondence: Cenk Akay, Assistant Professor, Department of Educational Sciences, Faculty of Education, Mersin University, Yenisehir Campus, Mersin, Turkey 